\title{
Expiratory flow limitation and obstruction in the elderly
}

\author{
C. de Bisschop*, M.L. Marty", J.F. Tessier", P. Barberger-Gateau", \\ J.F. Dartigues ${ }^{\star}$ and H. Guénard ${ }^{+}$
}

ABSTRACT: Elderly people commonly suffer from dyspnoea, which may stem from expiratory flow limitation (EFL). The relationship between EFL, as assessed by the negative expiratory pressure method and spirometric indices, was investigated in an elderly French population. Subjects, aged 66-88 yrs, filled in socio-demographic and standardised questionnaires, which dealt with: medical history, smoking status and respiratory symptoms. EFL measurements and forced expiratory manoeuvres were performed.

Validated measurements were obtained in 750 out of 1,318 subjects: $47 \%$ were $E F L+(E F L>0)$, with a higher prevalence in females than in males. EFL and forced expiratory volume in one second (FEV 1 ) were correlated with age. A total of 116, from the 750 subjects, with no medical history and no symptoms, served as a healthy group. The prevalence of EFL+ subjects increased with the grade of dyspnoea and was highest in respiratory and cardiac patients when compared with the healthy subjects. EFL did not correlate with FEV 1 /forced vital capacity (FVC), the usual index of obstruction. Some elderly subjects (15\%) with dyspnoea but with no medical history, mainly females with small FVC and normal FEV1/FVC, had a greater EFL than the healthy subjects.

In elderly people, expiratory flow limitation measurements, along with the usual forced expiratory volume in one second/ forced vital capacity ratio, may be of value for the interpretation of dyspnoea.

KEYWORDS: Elderly, expiratory flow limitation, negative expiratory pressure

I $\mathrm{n}$ the elderly, chronic respiratory diseases and heart failure account for a large part of their comorbidity, often leading to dyspnoea. Chronic obstructive pulmonary disease (COPD), one of the most invalidating of respiratory diseases, is presently the fifth largest cause of mortality worldwide [1]. Heart failure, which can induce respiratory impairment, is also highly prevalent in the elderly; two-thirds of French cardiac patients are aged $>70$-yrs $[2,3]$. The worsening of lung or heart diseases induces dyspnoea, which tends to restrict the physical activity of elderly people. It would thus be of value to diagnose this condition in its early stages to avoid complications, and detection of respiratory impairment preceding the onset of dyspnoea would aid prevention. Since routine spirometry measurements are only weakly related to dyspnoea other assessments of pulmonary function are needed [4-6].

The diagnosis of expiratory flow limitation (EFL) has traditionally been based on the comparison of tidal and maximal flow/volume curves $[7,8]$.

For editorial comments see page 563 .
Another technique described by VALTA et al. [9], the negative expiratory pressure technique (NEP), can detect EFL during tidal breathing. The NEP is a noninvasive and non-effort-dependent technique finding favour in the elderly who may be unable to perform forced expiratory manoeuvres [10]. With this method, a negative pressure is applied at the mouth during spontaneous expiration, increasing the expiratory driving pressure and consequently the expiratory flow. This technique has been applied and validated by VALTA et al. [9] in mechanically ventilated patients and KOULOURIS et al. [11] in resting patients with COPD. forced expiratory manoeuvre following a full inspiration, as expiratory limitation with the NEP technique is assessed during tidal breathing. Maximum forced flow/volume curve-derived variables and expiratory flow limitation variables would not necessarily correlate. Moreover, ELTAYARA et al. [5] have shown in COPD that chronic dyspnoea was better associated with a five-point flow limitation score assessed by the NEP technique than with routine function tests.
Variables defining obstruction are derived from a
AFFILIATIONS

*Laboratoire des Adaptations Physiologiques aux Activités Physiques EA 3813, Faculté des Sciences du Sport, Poitiers, and \# Laboratoire Santé Travail Environnement EA 3672, Institut de Santé Publique d'Epidémiologie et de Développement (ISPED), 'INSERM U593, ISPED, and +Laboratoire de Physiologie, EA518, Faculté Victor Pachon, Université Bordeaux 2, Bordeaux, France.

CORRESPONDENCE

C. de Bisschop

Laboratoire des Adaptations

Physiologiques aux Activités Physiques

Faculté des Sciences du Sport

4 allée Jean Monnet 86000 Poitiers France

Fax: 33549453396

E-mail: Claire.de-Bisschop@mshs. univ-poitiers.fr

Received:

November 192004

Accepted after revision:

May 302005

SUPPORT STATEMENT

The study was supported by GlaxoSmithKline (Bordeaux, France).

European Respiratory Journal Print ISSN 0903-1936 Online ISSN 1399-3003 
Since the association between the level of dyspnoea and the degree of airway obstruction is not close and the forced expiratory manoeuvre is difficult to obtain in the elderly, the current authors hypothesised if the expiratory flow limitation, as assessed by the NEP technique, might be a better lung function index of dyspnoea.

\section{SUBJECTS AND METHODS \\ Design of the quid $R$ elderly cohort and data collection at entry time}

A total of 2,612 Caucasian subjects aged 66-88 yrs, which lived at home in the suburb of Bordeaux (France), were selected from electoral rolls to take part in the study [12]. Only subjects with an acute disease were rejected. The study was approved by the University Hospital of Bordeaux ethics committee. All the subjects were informed of the conditions related to the study and gave their written, informed consent.

The subjects were interviewed at home by a psychologist who administered a questionnaire concerning sociodemographic parameters, use of medication and eating habits. A medical work-up was then performed in a mobile unit. A standardised questionnaire concerning medical history, smoking and respiratory symptoms including dyspnoea grade [13] was administered and anthropometric, NEP and spirometric measurements were performed.

\section{Negative expiratory pressure technique measurements}

Subjects were tested for their response to a 5 hectopascal NEP. A flow meter was connected on one side to the mouthpiece and on the other side to a Venturi device receiving compressed air ( 3 bar) from a tank at the onset of some expirations by activating an electro valve. After a few cycles of adaptation, the NEP was automatically applied at the onset of expiration. The flow/volume curve in response to NEP was compared with the previous cycle (Ctrl cycle; fig. 1). The measurement was accepted if the difference between end-inspiratory volumes did not differ $>10 \%$ between the two cycles and if the expiratory volume during NEP was equal to or greater than the control. A total of six cycles were performed by the subjects. Data were retained if two out of the six cycles were validated. The EFL was defined as the percentage of expiratory volume for which the expiratory flow with NEP became equal to the flow of the control breath. Subjects with $E F L=0$ were considered nonflow limited (NFL), while those with EFL $>0$ were classified EFL+. The mean-mid expiratory flow between 25 and $75 \%$ of tidal volume (TMEF) was calculated, along with the difference between NEP and Ctrl TMEF (Delta TMEF).

\section{Forced expiratory manoeuvres}

Expiratory manoeuvres were performed with a flow/volume device calibrated daily with a 2 L syringe (Medisoft, Dinant, Belgium). Three forced expiratory manoeuvres with forced expiratory volume in one second (FEV1) differing by $<5 \%$ were performed. Forced vital capacity (FVC), FEV1 and mid expiratory flow (MEF25-75\%) were calculated.

\section{Groups}

Subjects were initially classified according to symptoms, medical history and smoking status. The subjects with no symptoms and no medical history were pooled in the three groups: fully healthy subjects (healthy), former and current

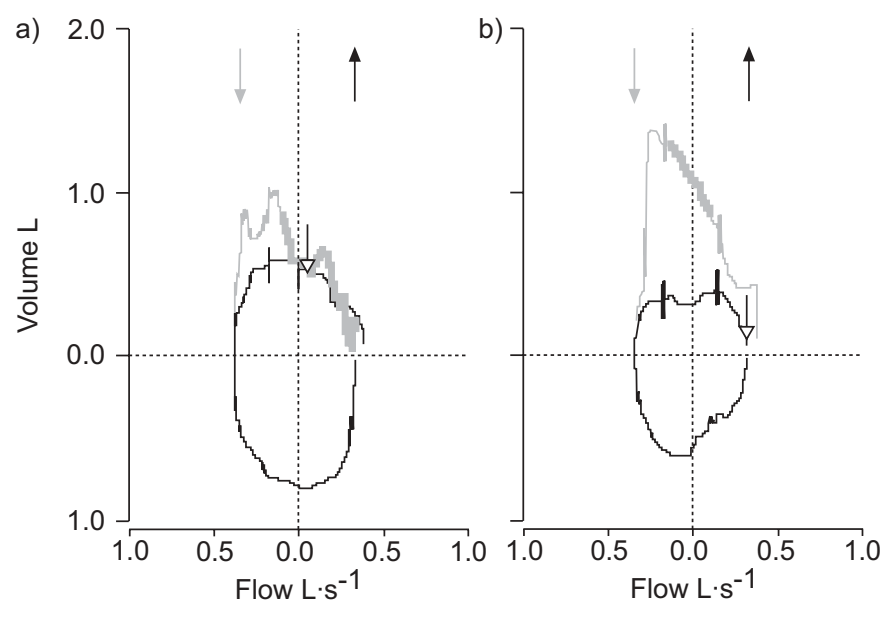

FIGURE 1. a) Flow/volume loops before and during a 5 hectopascal negative expiratory pressure technique (black trace) from an expiratory limited female with dyspnoea (grade 2) with no medical history, in the expiratory limitation and dyspnoea due to age group. The female was: aged $74 \mathrm{yrs}, 1.44 \mathrm{~m}$ in height and weighed $64 \mathrm{~kg}$. The subject had a forced expiratory volume (FEV1) of $1.21 \mathrm{~L}$, a forced vital capacity (FVC) of $1.53 \mathrm{~L}$ and a FEV1/FVC ratio of $79.1 \%$. b) A healthy 71 yr-old female, with a height of $1.55 \mathrm{~m}$, a weight of $53 \mathrm{~kg}$, a FEV1 of $1.76 \mathrm{~L}$, a FVC of $2.25 \mathrm{~L}$ and a FEV $1 / F V C$ ratio of $78.5 \%$. The grey arrow denotes the beginning of the negative expiratory pressure technique (NEP) and the black arrows denote the end of the NEP. The open arrow denotes limitation. The grey traces represent the flowvolume curves while the subjects breathed with NEP.

smokers (AsSmok, for asymptomatic smokers), and treated systemic hypertension (AsHT). Individuals with dyspnoea or medical history (respiratory/cardiac) were pooled in the symptomatic group.

\section{Data analysis}

Data are expressed as mean $\pm \mathrm{SD}$. Correlations were obtained by linear regression analysis and by Spearman's rank correlation for EFL. Differences were evaluated by unpaired t-tests and ANOVA). Nonparametric tests (Kruskal-Wallis ANOVA Mann-Whitney U-test and Chi-squared test) were used to analyse the EFL data. Multiple linear regressions were employed to evaluate EFL, Delta TMEF and FEV1/FVC as independent or complementary predictors of dyspnoea. Values of $\mathrm{p}<0.05$ were considered statistically significant.

\section{RESULTS}

A total of 1,318 subjects completed the forced expiratory manoeuvres, of which 828 had valid measurements according to standard criteria [14]. A total of 750 subjects had validated flow/volume loops and responses to NEP. The distribution of the subjects, according to their symptoms and medical history, is schematically described in figure 2. The mean age of the subjects was $73.9 \pm 4.7$ yrs. Data derived from the respiratory and cardiac questionnaires are listed respectively in tables 1 and 2. Overall, $46.9 \%$ of the subjects were EFL+. Mean Delta TMEF was $0.4 \pm 0.3 \mathrm{~L} \cdot \mathrm{s}^{-1}$ for EFL subjects (range $-0.4-1.6 \mathrm{~L} \cdot \mathrm{s}^{-1}$ ) and $1.0 \pm 0.6 \mathrm{~L} \cdot \mathrm{s}^{-1}$ for NFL subjects (range $0.07-3.8 \mathrm{~L} \cdot \mathrm{s}^{-1}$ ). EFL was correlated with body mass index (BMI; $\mathrm{p}<0.001)$. EFL+ was more common in females than in males (51.5 versus $41.7 \%$, $\mathrm{p}=0.007)$, as there was no difference in their BMI. 


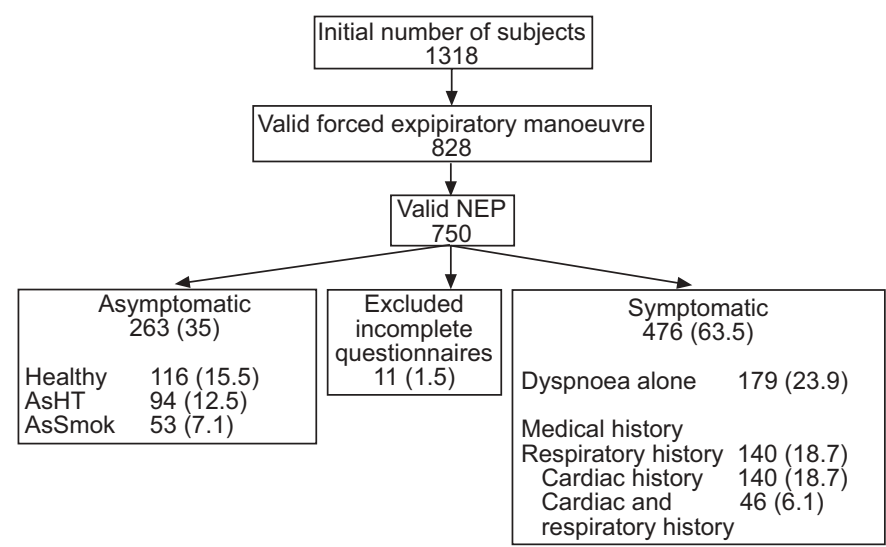

FIGURE 2. Distribution of the subjects as function of the presence of symptoms and their medical history. Data presented as $\mathrm{n}$ or $\mathrm{n}(\%)$. NEP: negative expiratory pressure technique; AsHT: subjects with treated systemic hypertension; AsSmok: asymptomatic smokers.

\section{Expiratory flow limitation, FEV1 and FVC in the healthy group}

EFL in the healthy group was correlated with age in both sexes $(\mathrm{p}<0.03)$. The prevalence of EFL at aged $<80$ yrs and $>80 \mathrm{yrs}$ was 20 versus $86 \%(p<0.01)$ in males and 33 versus $67 \%$

\begin{tabular}{|c|c|c|}
\hline TABLE 1 & \multicolumn{2}{|c|}{$\begin{array}{l}\text { Results obtained from the respiratory } \\
\text { questionnaire }\end{array}$} \\
\hline \multicolumn{3}{|l|}{ Wheezing } \\
\hline Yes & & $51(6.8)$ \\
\hline No & & 685 (91.3) \\
\hline Does not kn & & $14(1.9)$ \\
\hline \multicolumn{3}{|l|}{ Sputum } \\
\hline Yes & & $76(10.1)$ \\
\hline No & & $658(87.7)$ \\
\hline Does not kn & & $16(2.1)$ \\
\hline \multicolumn{3}{|l|}{ Cough } \\
\hline Yes & & $94(12.5)$ \\
\hline No & & $640(85.3)$ \\
\hline Does not kn & & $16(2.1)$ \\
\hline \multicolumn{3}{|l|}{ Asthma } \\
\hline Yes & & $59(7.9)$ \\
\hline Confirmec & & $54(7.2)$ \\
\hline No & & 668 (89.1) \\
\hline Does not kn & & $23(3.1)$ \\
\hline \multicolumn{3}{|c|}{ Dyspnoea (grade) } \\
\hline Never $(0)$ & & $374(49.9)$ \\
\hline For intense & ffort (1) & $285(38)$ \\
\hline For modera & activities (2) & $74(9.9)$ \\
\hline For life activ & ties (3) & $10(1.3)$ \\
\hline At rest (4) & & $2(0.3)$ \\
\hline Does not kn & & $5(0.7)$ \\
\hline \multicolumn{3}{|c|}{ Smoking status } \\
\hline Never & & $454(60.5)$ \\
\hline Former & & $233(31.1)$ \\
\hline Current & & $63(8.4)$ \\
\hline
\end{tabular}

Data are presented as $n(\%)$.
TABLE 2 Results obtained from the cardiac questionnaire

\begin{tabular}{lc} 
Angina pectoris & \\
Yes & $66(8.8)$ \\
No & $659(87.9)$ \\
Does not know & $25(3.3)$ \\
Arythmia & \\
Yes & $105(14)$ \\
No & $622(82.9)$ \\
Does not know & $23(3.1)$ \\
Cardiac insufficiency & \\
Yes & $47(6.3)$ \\
No & $678(90.4)$ \\
Does not know & $25(3.3)$ \\
Myocardial infarction & \\
Yes & $39(5.2)$ \\
No & $693(92.4)$ \\
Does not know & $18(2.4)$ \\
Angioplasty & \\
Yes & $17(2.3)$ \\
No & $719(95.9)$ \\
Does not know & $14(1.9)$ \\
Coronary bypass & \\
Yes & $22(2.9)$ \\
No & $714(95.2)$ \\
Does not know & $14(1.9)$ \\
Cardiac surgery & \\
Yes & $19(2.5)$ \\
No & $718(95.7)$ \\
Does not know & $13(1.7)$ \\
\hline
\end{tabular}

Data are presented as $n(\%)$.

$(\mathrm{p}=0.057)$ in females. EFL was negatively correlated with FVC in females $(\mathrm{p}=0.01)$.

FEV1 was correlated with height in females $(p<0.01)$ and inversely correlated with age in both sexes. FEV1 and FVC in males were significantly greater than in females $(p<0.001)$, with no difference in FEV1/FVC (table 3). Regression equations in the 116 healthy males (1) and females (2) were:

$$
\begin{aligned}
& \mathrm{FEV}_{1}=(-0.036 \times \text { age })+5.27 \\
& \mathrm{FEV}_{1}=(-0.029 \times \text { age })+(0.034 \times \text { height })-1.23
\end{aligned}
$$

These equations were used to calculate the value for FEV1 predicted percentage in the remaining three groups. For FVC, the equation for females was:

$$
\mathrm{FVC}=(-0.027 \times \text { age })+(0.047 \times \text { height })-2.86
$$

While there was no correlation in males, either with age or height, mean FVC in males was $3.33 \pm 0.73 \mathrm{~L}$.

\section{Expiratory flow limitation, FEV 1 and FVC in the three other groups}

In the symptomatic group, females had a significantly higher prevalence of EFL than males $(p=0.001)$ although FEV1/FVC was lower in the males. All the respiratory variables for the 
TABLE 3 Respiratory variables in the four groups of subjects

\begin{tabular}{|c|c|c|c|c|c|c|}
\hline & Subjects $n$ & EFL \% EFL+ & Delta TMEF L. $\mathrm{s}^{-1}$ & FEV $1 \%$ pred & FVC L & FEV1/FVC \\
\hline \multicolumn{7}{|l|}{ Healthy } \\
\hline Female & 79 & 38 & $0.76 \pm 0.49$ & $100.19 \pm 16.67$ & $2.37 \pm 0.53$ & $79.52 \pm 7.37$ \\
\hline \multicolumn{7}{|l|}{ AsHT } \\
\hline Male & 51 & 43 & $0.92 \pm 0.73$ & $98.87 \pm 20.12$ & $3.26 \pm 0.70^{\#}$ & $79.35 \pm 7.74$ \\
\hline \multicolumn{7}{|l|}{ AsSmok } \\
\hline Male & 42 & 24 & $1.05 \pm 0.65^{\#}$ & $102.21 \pm 20.03$ & $3.56 \pm 0.63^{\#}$ & $76.91 \pm 7.94$ \\
\hline Female & 11 & 54.5 & $0.64 \pm 0.27$ & $92.31 \pm 15.87$ & $2.32 \pm 0.42$ & $76.95 \pm 8.65$ \\
\hline \multicolumn{7}{|c|}{ Symptomatic } \\
\hline Male & 214 & $46^{\#}$ & $0.75 \pm 0.56^{\#}$ & $90.9 \pm 23.93^{\circ}$ & $3.16 \pm 0.73^{\#}$ & $74.95 \pm 0.18^{\#}$ \\
\hline Female & 262 & $57.5^{\circ}$ & $0.59 \pm 0.46^{\circ}$ & $90.9 \pm 19.72$ & $2.17 \pm 0.45^{\circ}$ & $78.46 \pm 8.27$ \\
\hline
\end{tabular}

females within this group, except for FEV1/FVC, were different from that of the healthy females, whereas for the males only the FEV1 \% pred was affected. For both sexes, in the symptomatic group, BMI was higher when compared with the healthy group (males: $27.5 \pm 3.6 \mathrm{~kg} \cdot \mathrm{m}^{-2}$ versus $25.6 \pm 3.3 \mathrm{~kg} \cdot \mathrm{m}^{-2}$; females: $27.7 \pm 4.9 \mathrm{~kg} \cdot \mathrm{m}^{-2}$ versus $\left.25 \pm 4 \mathrm{~kg} \cdot \mathrm{m}^{-2} ; \mathrm{p}<0.02\right)$ and EFL was significantly correlated to BMI.

For the males within the three groups, EFL was negatively correlated to FVC $(\mathrm{p}<0.05)$. EFL was correlated neither with FEV1/FVC nor with FEV1 \% pred in any of the groups for females, while this correlation was only significant in the males in the symptomatic group $(p=0.02)$. In the AsHT and symptomatic groups FEV1 and FVC were correlated with height $(p<0.01)$ and inversely correlated with age $(p<0.05)$ for both sexes. The AsSmok group of females was too small to draw any specific conclusions; in the males the FEV1 decreased with age.

\section{Relationship between respiratory variables and dyspnoea and/or medical status in the overall population}

After adjusting for age, sex, height, dyspnoea, wheezing, cough, sputum, asthma and smoking, significant associations in the overall population were found between the following: 1) EFL and dyspnoea and wheezing; 2) Delta TMEF and sex and dyspnoea; 3) FEV1/FVC and dyspnoea, wheezing and asthma (table 4).

EFL, in the whole population, increased significantly as the grade of dyspnoea increased $(\mathrm{p}<0.01)$. The prevalence of EFL

TABLE 4 Multiple linear regressions devised on the overall population

\begin{tabular}{|c|c|c|c|c|c|c|}
\hline & \multicolumn{2}{|c|}{ EFL } & \multicolumn{2}{|c|}{ Delta TMEF } & \multicolumn{2}{|c|}{$\mathrm{FEV}_{1 / \mathrm{FVC}}$} \\
\hline & $\boldsymbol{\beta} \pm \mathrm{SE}$ & p-value & $\boldsymbol{\beta} \pm \mathrm{SE}$ & p-value & $\boldsymbol{\beta} \pm \mathbf{S E}$ & p-value \\
\hline Sex & $0.07 \pm 0.05$ & 0.20 & $-13.48 \pm 5.98$ & 0.02 & $1.57 \pm 0.94$ & 0.09 \\
\hline Age & $0.01 \pm 0.00$ & 0.19 & $-0.70 \pm 0.44$ & 0.11 & $0.00 \pm 0.07$ & 0.95 \\
\hline Height & $0.00 \pm 0.00$ & 0.58 & $0.33 \pm 0.33$ & 0.32 & $-0.07 \pm 0.05$ & 0.17 \\
\hline Dyspnoea & $0.19 \pm 0.06$ & 0.00 & $-15.27 \pm 6.67$ & 0.02 & $-2.64 \pm 1.05$ & 0.01 \\
\hline Wheezing & $0.20 \pm 0.08$ & 0.02 & $-11.43 \pm 9.28$ & 0.22 & $-4.87 \pm 1.46$ & 0.00 \\
\hline Cough & $0.02 \pm 0.09$ & 0.79 & $-3.61 \pm 9.59$ & 0.71 & $2.52 \pm 1.51$ & 0.10 \\
\hline Sputum & $-0.06 \pm 0.10$ & 0.50 & $-4.12 \pm 10.52$ & 0.70 & $-1.63 \pm 1.65$ & 0.32 \\
\hline Asthma & $0.07 \pm 0.07$ & 0.36 & $-9.82 \pm 8.02$ & 0.22 & $-4.43 \pm 1.26$ & 0.00 \\
\hline Smoking status & $0.09 \pm 0.07$ & 0.21 & $-14.56 \pm 8.19$ & 0.08 & $-1.08 \pm 1.29$ & 0.40 \\
\hline Constant & $0.26 \pm 0.61$ & 0.67 & $83.77 \pm 67.05$ & 0.21 & $88.71 \pm 10.53$ & 0.00 \\
\hline Adjusted $r^{2}$ & \multicolumn{2}{|c|}{0.038} & \multicolumn{2}{|c|}{0.048} & \multicolumn{2}{|c|}{0.075} \\
\hline
\end{tabular}

EFL: expiratory flow limitation; TMEF: the mean-mid expiratory flow between 25 and $75 \%$ of tidal volume; FEV1: forced expiratory volume in one second; FVC: forced vital capacity; $r^{2}$ : coefficient determination. 


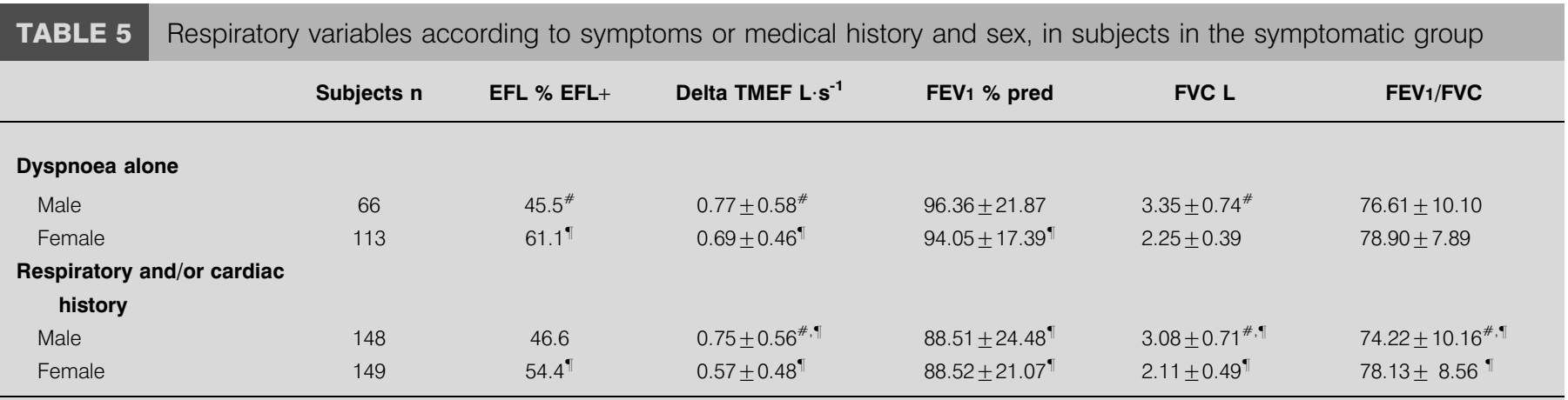

Data are presented as mean $\pm S D$, unless otherwise stated. EFL: expiratory flow limitation, measured as percentage of subjects with EFL $>0$ (\% EFL+); TMEF: the meanmid expiratory flow between 25 and $75 \%$ of tidal volume; FEV1 \% pred: forced expiratory volume in one second percentage predicted: FVC: forced vital capacity. ${ }^{\#}$ : males significantly different from females; ${ }^{\bullet}$ : significantly different from healthy subjects.

was also significantly increased according to the dyspnoea grades, 39, 51 and $69 \%$ for dyspnoea grade 0,1 and $2-4$ respectively $(\mathrm{p}<0.01)$. FEV1 \% pred, FEV1 and FVC were significantly decreased as the grade of dyspnoea increased $(p<0.01)$. FEV1/FVC was only decreased in the most dyspnoeic subjects (2-4) as compared with the nondyspnoeic subjects $(\mathrm{p}<0.01)$.

\section{Relationship between respiratory variables and dyspnoea and/or medical status in the symptomatic group}

The detailed results concerning the symptomatic group are presented in tables 5 and 6 . The prevalence of former and current smokers in the symptomatic group was $40 \%(n=192)$. Among the 179 subjects of the symptomatic group with no medical history, but with dyspnoea, 111 nonsmoking subjects (76\% with dyspnoea grade 1 ) were selected. This subgroup of subjects was named the ELDA group (expiratory limitation and dyspnoea due to age). ELDA males and females did not differ from healthy subjects for age and height but females differed for BMI $\left(27.7 \pm 4.4 \mathrm{~kg} \cdot \mathrm{m}^{-2} ; \mathrm{p}<0.01\right)$. EFL was significantly greater $(\mathrm{p}<0.02)$ and FVC and FEV1 \% pred significantly lower $(\mathrm{p}<0.05)$ in ELDA females compared with healthy females (fig. 3), while FEV1/FVC was not different. There was no difference in males. No correlation was observed between EFL and FEV1/FVC in ELDA in either sex.

\section{DISCUSSION}

The main findings of the present study were: 1) EFL, an index of expiratory limitation is independent of FEV1/FVC, the usual index of obstruction, in most groups of elderly subjects; 2) EFL, as $\mathrm{FEV}_{1} \%$ pred, was related to the grade of dyspnoea; 3) some elderly people, mainly female, suffering from dyspnoea with no medical history or a decrease in FEV1/FVC, appeared to be more expiratory flow limited than others without dyspnoea.

\section{Population}

The present study's population was initially, randomly, selected from electoral rolls. In a second phase, these individuals were asked to participate in the respiratory study in a mobile unit. Many of the individuals did not attend the second phase; either they did not wish to or were unable due to disability. The final population studied was thus not truly representative of the whole population. Moreover, some elderly participants did not perform valid forced expiratory manoeuvres or did not manage to breath during NEP. It is, therefore, anticipated that the percentage of symptomatic patients was underestimated.

\section{Methodological aspects}

Valid measurements of maximal expiratory flow and response to NEP were obtained in 750 subjects from a total of 1,318

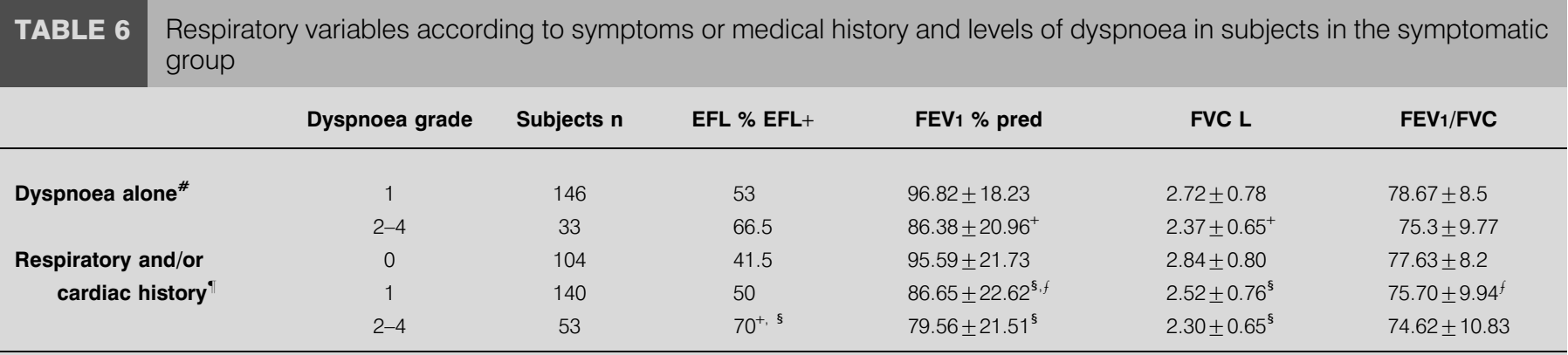

Data presented as $n$ or mean \pm SD. EFL: expiratory flow limitation measured as percentage of subjects with $E F L>0$ (\% EFL+); FEV1: forced expiratory volume in one second; FVC: forced vital capacity. ${ }^{\#}: \mathrm{n}=66$ (males), 113 (females); ${ }^{\bullet}: \mathrm{n}=148$ (males), 149 (females); ${ }^{+}$: significantly different from dyspnoea $1 ;^{\text {s. }}$ : significantly different from dyspnoea $0: f$ : for a same level of dyspnoea, significantly different from dyspnoea only group. 


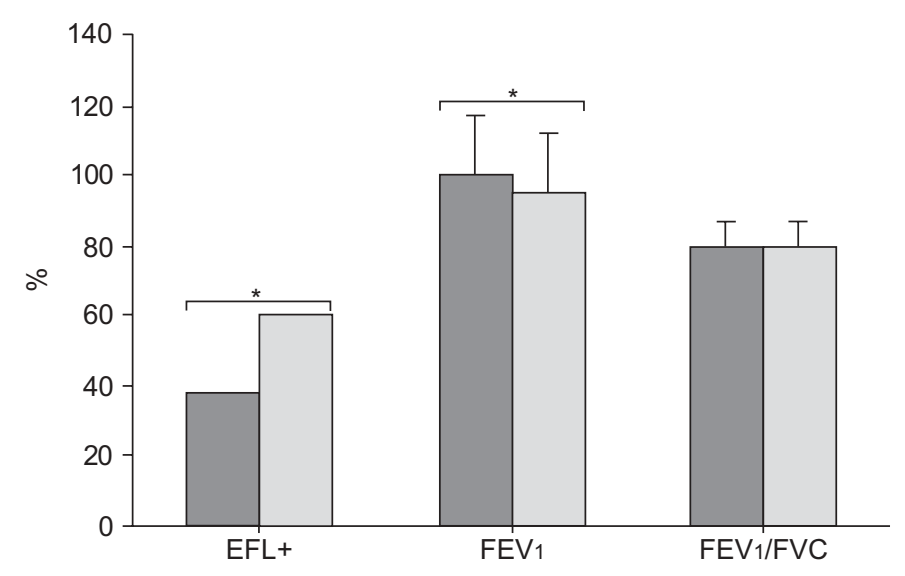

FIGURE 3. Prevalence of expiratory flow limitation in ELDA (expiratory limitation and dyspnoea due to age; $\square$ ) and healthy females ( $\square$ ). EFL+: expiratory flow limitation $>0$; FEV1: forced expiratory volume in one second; FVC: forced vital capacity. *: $p<0.05$, significantly different from healthy females.

participants. Most of the invalid measurements were observed with forced expiration ( $37 \%$ of the initial population sample), as only $9 \%$ of the participants did not manage to produce valid NEP data. The figure for invalid forced expiration manoeuvres was greater than that reported by WATERER et al. [15] (11.4\%). However, the study by WATERER et al. [15] excluded all people with a medical history, thereby including only healthy subjects, whereby in the present study only a few healthy subjects $(15.5 \%)$ were tested. It is likely that disabled individuals were less likely to succeed, when compared with those in good health, in performing forced expiratory manoeuvres. Moreover, DE FILIPPI et al. [16] who studied a population older than the present one (mean age $80.2 \mathrm{yrs}$ ) reported that many forced expirations in elderly subjects do not meet the American Thoratic Society criteria. By contrast, the flow response to NEP was more successful as it required less cooperation. A low level of NEP was used to reduce the occurrence of upper airway collapsibility. As the increase in expiratory flow during NEP is a function of airway resistance, the current authors tried to only validate cycles that started at the same end-inspiratory volume. Tidal volume during NEP was not taken into account, unless smaller than the control, as neither EFL nor Delta TMEF are influenced by tidal volume.

Interestingly, in most groups, EFL, an index of limitation, was not correlated with FEV1/FVC, the usual index of obstruction. This discrepancy is comprehensible since limitation with the NEP technique is assessed during normal tidal breathing, i.e. in a small part of the volume range above the functional residual capacity, as FEV1/FVC is obtained after a full inspiration. Some putative associations between limitation and obstruction could be defined: 1) both limitation and obstruction, as for example in severe COPD patients; 2) limitation but no obstruction, as in the ELDA subjects; 3) obstruction but no limitation. This last figure could comprise patients with slight obstruction and a large expiratory reserve volume.

On a theoretical basis, four different "respiratory" variables could have been compared with the medical status of the participants: EFL, FEV1, inspiratory capacity, and forced inspiratory volume in one second [17]. The current authors did not assess the last two variables. Inspiratory capacity is difficult to perform without previous training procedures. Forced inspiration was not performed as the priority was given to the reliability of forced expiration.

\section{Age and respiratory variables}

Only $15.5 \%$ of the population (37 males and 79 females) were classified in the healthy group, used to define predicted values. The same percentage of healthy people was obtained by ENRIGHT et al. [18] in their population using the same criteria. Several studies have attempted to evaluate the decline in FVC and FEV1 with age in elderly cohorts [19-26]. Interestingly, ENRIGHT et al. [18] compared their reference equation (Cardiovascular Health Study) with those of four previous studies [19-22]. The values of FEV1 and FVC in females, in the present study, were higher than those of DOCKERY et al. [21] and very close to those of the four other studies, with a decline of $29 \mathrm{~mL} \cdot \mathrm{yr}^{-1}$ for FEV1 and of $27 \mathrm{~mL} \cdot \mathrm{yr}^{-1}$ for FVC. In the males, values of FEV1 obtained from the healthy equation based only on age were very close to those reported by DOCKERY et al. [21], with a decline of $36 \mathrm{~mL} \cdot \mathrm{yr}^{-1}$. The lack of correlation between FEV1 and height as between FVC and age or height in the current study's male participants was attributed to the small number of subjects included in this group. If healthy subjects and former-smokers data were pooled these correlations became significant. Nevertheless, they were not pooled as there were marked differences in the females between healthy and former smokers.

EFL was age dependant. This age dependency was probably due to the decrease in FVC with age. In females, FVC was strongly correlated with age $(\mathrm{p}<001)$. The link between EFL and FVC is supported by the fact that ELDA females, who were EFL+ without disease, had lower FVC than healthy subjects.

\section{Hypertension and respiratory variables}

As a high systolic blood pressure has been described as a strong predictor of reduced FEV1 and FVC [18, 26, 27], attention was focussed on the data of subjects reporting hypertension. The subjects without any symptoms, but reporting hypertension (AsHT), did not show any alteration in FEV1 and EFL in comparison with healthy subjects. All the patients with hypertension were treated, suggesting that the therapy may have had a favourable influence on lung function.

\section{Smoking and respiratory variables}

Although a majority of the smokers were classified in the symptomatic group, a subgroup (AsSmok) of current and former smokers with no symptoms or disease could be isolated. This group included mainly males whose values were not significantly different from those of the healthy group except for FEV1/FVC, which was slightly lower. The present observations suggest that in some people, smoking does not have the predicted deleterious effect on respiratory function $[24,26]$. However, these males had a higher FEV1 and FVC than the healthy subjects of the same age and height, suggesting that they benefited from higher adult lung volumes than the others. 


\section{Cardiac and/or respiratory impairments and respiratory variables}

Respiratory or cardiac diseases were obviously associated on average with marked alterations in respiratory function variables. An analysis of the relationships of the specific respiratory or cardiac diseases with the respiratory variables is out of the scope of this study.

\section{ELDA group}

In the present study, half of the cohort was dyspnoeic and nearly half $(46.9 \%)$ had EFL. Moreover, $15 \%$ of the cohort, for the most part females, was dyspnoeic, albeit free from cardiopulmonary disease (ELDA group). This result is in agreement with the data reported by LANDAHL et al. [28] obtained on a 70-yr-old population. The high prevalence of females in the ELDA group may be explained by the fact that height is a significant predictor of dyspnoea [5]. Given that females are smaller than males they have lower FVC and, therefore, more EFL and dyspnoea. This effect is probably accentuated by ageing, as people, mainly females, shrink with age. Indeed, although the authors did not observe any difference in height between healthy and ELDA females, FVC and FEV1 \% pred were smaller and BMI was higher in the ELDA females. The decrease in FVC has been shown to be associated with a decrease in the maximal available ventilation, which is a strong predictor of dyspnoea [5]. Obesity is also known to contribute to symptoms of dyspnoea [29, 30]. The increase in BMI and the reduction in FVC by enhancing respiratory limitation may thus be determinants of dyspnoea in the elderly, even in the absence of associated cardiopulmonary disease.

In conclusion, the present data provides evidence that expiratory flow limitation, like dyspnoea, is common in the elderly; half of the current study's cohort being limited. Expiratory flow limitation is related to the grade of dyspnoea and is increased in subjects with respiratory and cardiac disease as compared with healthy subjects. Expiratory flow limitation as measured with the negative expiratory pressure technique during normal tidal breathing does not correlate with forced expiratory volume in one second/forced vital capacity, the usual index of obstruction obtained during a maximal expiratory manoeuvre. Finally, it seems that some elderly people with dyspnoea but with no medical history, mainly females, have expiratory flow limitations $>0$ due to low forced vital capacity.

\section{REFERENCES}

1 Murray CJ, Lopez AD. Alternative projections of mortality and disability by cause 1990-2020: Global Burden of Disease Study. Lancet 1997; 349: 1498-1504.

2 Delahaye F, Roth O, Aupetit JF, de Gevigney G. [Epidemiology and prognosis of cardiac insufficiency]. Arch Mal Coeur Vaiss 2001; 94: 1393-1403.

3 Duguet A, Tantucci C, Lozinguez O, et al. Expiratory flow limitation as a determinant of orthopnea in acute left heart failure. J Am Coll Cardiol 2000; 35: 690-700.

4 McGavin CR, Artvinli M, Naoe H, McHardy GJ. Dyspnoea, disability, and distance walked: comparison of estimates of exercise performance in respiratory disease. BMJ 1978; 2: 241-243.

5 Eltayara L, Becklake MR, Volta CA, Milic-Emili J. Relationship between chronic dyspnea and expiratory flow limitation in patients with chronic obstructive pulmonary disease. Am J Respir Crit Care Med 1996; 154: 1726-1734.

6 Teeter JG, Bleecker ER. Relationship between airway obstruction and respiratory symptoms in adult asthmatics. Chest 1998; 113: 272-277.

7 Hyatt RE. The interrelationships of pressure, flow, and volume during various respiratory maneuvers in normal and emphysematous subjects. Am Rev Respir Dis 1961; 83: 676-683.

8 Ingram RH Jr, Schilder DP. Effect of gas compression on pulmonary pressure, flow, and volume relationship. J Appl Physiol 1966; 21: 1821-1826.

9 Valta P, Corbeil C, Lavoie A, et al. Detection of expiratory flow limitation during mechanical ventilation. Am J Respir Crit Care Med 1994; 150: 1311-1317.

10 Vanpee D, Swine C, Delwiche JP, Delaunois L. Evaluation of flow limitation in elderly patients unable to perform a forced expiratory maneuver. Aging Clin Exp Res 2002; 14: 208-211.

11 Koulouris NG, Valta P, Lavoie A, et al. A simple method to detect expiratory flow limitation during spontaneous breathing. Eur Respir J 1995; 8: 306-313.

12 The 3C Study Group. Vascular factors and risk of dementia: design of the Three-City Study and baseline. characteristics of the study population. Neuroepidemiology 2003; 22: 316-325.

13 Fletcher CM. The natural history of chronic bronchitis and emphysema. New York, Oxford University Press; 1976.

14 Standardized Lung Function Testing. Official statement of the European Respiratory Society. Eur Respir J 1993; Suppl. 16: 1-100.

15 Waterer GW, Wan JY, Kritchevsky SB, et al. Airflow limitation is underrecognized in well-functioning older people. J Am Geriatr Soc 2001; 49: 1032-1038.

16 De Filippi F, Tana F, Vanzati S, Balzarini B, Galetti G. Study of respiratory function in the elderly with different nutritional and cognitive status and functional ability assessed by plethysmographic and spirometric parameters. Arch Gerontol Geriatr 2003; 37: 33-43.

17 Taube C, Lehnigk B, Paasch K, Kirsten DK, Jorres RA, Magnussen H. Factor analysis of changes in dyspnea and lung function parameters after bronchodilation in chronic obstructive pulmonary disease. Am J Respir Crit Care Med 2000; 162: 216-220.

18 Enright PL, Kronmal RA, Higgins M, Schenker M, Haponik EF. Spirometry reference values for women and men 65 to 85 years of age. Cardiovascular health study. Am Rev Respir Dis 1993; 147: 125-133.

19 Crapo RO, Morris AH, Gardner RM. Reference spirometric values using techniques and equipment that meet ATS recommendations. Am Rev Respir Dis 1981; 123: 659-664.

20 Knudson RJ, Lebowitz MD, Holberg CJ, Burrows B. Changes in the normal maximal expiratory flow-volume curve with growth and aging. Am Rev Respir Dis 1983; 127: 725-734. 
21 Dockery DW, Ware JH, Ferris BG Jr, et al. Distribution of forced expiratory volume in one second and forced vital capacity in healthy, white, adult never-smokers in six U.S. cities. Am Rev Respir Dis 1985; 131: 511-520.

22 Morris JF, Koski A, Temple WP, Claremont A, Thomas DR. Fifteen-year interval spirometric evaluation of the Oregon predictive equations. Chest 1988; 93: 123-127.

23 Smolej-Narancic N, Pavlovic M, Rudan P. Ventilatory parameters in healthy nonsmoking adults of Adriatic islands (Yugoslavia). Eur Respir J 1991; 4: 955-964.

24 Sherrill DL, Lebowitz MD, Knudson RJ, Burrows B. Longitudinal methods for describing the relationship between pulmonary function, respiratory symptoms and smoking in elderly subjects: the Tucson Study. Eur Respir J 1993; 6: 342-348.

25 McClaran SR, Babcock MA, Pegelow DF, Reddan WG, Dempsey JA. Longitudinal effects of aging on lung function at rest and exercise in healthy active fit elderly adults. J Appl Physiol 1995; 78: 1957-1968.

26 Griffith KA, Sherrill DL, Siegel EM, Manolio TA, Bonekat HW, Enright PL. Predictors of loss of lung function in the elderly: the Cardiovascular Health Study. Am J Respir Crit Care Med 2001; 163: 61-68.

27 Zureik M, Benetos A, Neukirch C, et al. Reduced pulmonary function is associated with central arterial stiffness in men. Am J Respir Crit Care Med 2001; 164: 2181-2185.

28 Landahl S, Steen B, Svanborg A. Dyspnea in 70-year-old people. Acta Med Scand 1980; 207: 225-230.

29 Ferretti A, Giampiccolo P, Cavalli A, Milic-Emili J, Tantucci C. Expiratory flow limitation and orthopnea in massively obese subjects. Chest 2001; 119: 1401-1408.

30 Pankow W, Podszus T, Gutheil T, Penzel T, Peter J, Von Wichert P. Expiratory flow limitation and intrinsic positive end-expiratory pressure in obesity. J Appl Physiol 1998; 85: 1236-1243. 